\title{
Rise in Intracellular Calcium via a Nongenomic Effect of Allopregnanolone in Fetal Rat Hypothalamic Neurons
}

\author{
Govindan Dayanithi and Lucia Tapia-Arancibia \\ Laboratoire de Neurobiologie Endocrinologique, URA 1197 CNRS, Université Montpellier II, F-34095 Montpellier, \\ Cedex 5, France
}

This study examines the early effects of $3 \alpha$-hydroxy-5 $\alpha$-pregnan-20-one (allopregnanolone) on cytosolic free calcium concentration $\left(\left[\mathrm{Ca}^{2+}\right]_{i}\right)$ in primary cultures of fetal rat hypothalamic neurons. Microspectrofluorimetry of fluorescent $\mathrm{Ca}^{2+}$-sensitive indicator Fura-2 was used to quantify these changes. Allopregnanolone (1 pM to $100 \mathrm{~nm}$ ) increased $\left[\mathrm{Ca}^{2+}\right]_{1}$ within $2-3 \mathrm{sec}$, in a dose-dependent manner, with an $\mathrm{EC}_{50}$ of $10 \pm 4 \mathrm{~nm}$. The stimulatory effect of allopregnanolone was attributable principally to a $\mathrm{Ca}^{2+}$ influx, as shown by the strong inhibition of external $\mathrm{Ca}^{2+}$ removal or by the calcium channel blocker nifedipine. The effect was stereospecific because the allopregnanolone isomer $3 \beta$-hydroxy-5 $\alpha$-pregnan-20-one had no effect on $\left[\mathrm{Ca}^{2+}\right]_{\mathrm{i}}$. Among two other steroids examined, progesterone had no effect on $\left[\mathrm{Ca}^{2+}\right]_{i}$, but $17 \beta$-estradiol evoked a rise in $\left[\mathrm{Ca}^{2+}\right]_{1}$, although to a lesser extent than allopregnanolone. The allopregnanolone-induced $\left[\mathrm{Ca}^{2+}\right]_{i}$ rise was inhibited by picrotoxin and bicuculline but was unaffected by tetrodotoxin or by pretreatment of neurons with pertussis toxin. These results are consistent with a membrane site of action for allopregnanolone associated with $\mathrm{GABA}_{A}$ receptors, leading to rapid changes in $\left[\mathrm{Ca}^{2+}\right]_{i}$ in fetal rat hypothalamic neurons.

Key words: neurosteroids; calcium; hypothalamic neurons; Fura-2; allopregnanolone; nongenomic effect; $G A B A_{\mathrm{A}}$ receptor
The term "neurosteroids" was introduced by Baulieu (1981) to describe the steroids synthesized in brain tissue from cholesterol or from steroid hormone precursors (Robel and Baulieu, 1990, 1994; Baulieu, 1991; Orchinick and McEwen, 1993). According to their effects, they can be considered "neuroactive steroids." This term, coined by Paul and Purdy (1992), includes all steroids that are active on neuronal tissue regardless of whether they are synthesized in the brain.

Aside from the classical genomic actions of steroids (McEwen, 1991a), these substances may alter rapidly the excitability of neurons. In fact, the ability of certain steroids and their metabolites to influence brain activity, including firing rate of neurons, induction of sedation, anesthesia, neurosecretion, and behavioral changes, is well known (Schumacher, 1990; McEwen, 1991b). However, the mechanisms involved in these actions are not well understood. Recently, Ramirez et al. (1990) demonstrated that progesterone and its metabolites can modify neuronal secretion by acting through a nongenomic transmembrane-signaling mechanism. They postulated that progesterone could open $\mathrm{Ca}^{2+}$ channels of nerve terminals leading to a rapid neuronal secretion. Evidence suggesting a role of $\mathrm{Ca}^{2+}$ in this phenomenon was provided previously by Drouva et al. (1985), who showed that omission of $\mathrm{Ca}^{2+}$ in the medium or addition of D-600, a $\mathrm{Ca}^{2+}$ channel blocker, antagonized the stimulatory effect of progester-

\footnotetext{
Received June 19, 1995; revised Sept. 15, 1995; accepted Sept. 26, 1995

This work was supported by grants from CNRS and INSERM (CRE 910701). We thank Prof. Jorgc Belmar, Prof. I Iélène Astier, and Dr. Colin Ingram for valuable comments and critical reading of the manuscript, and $\mathrm{Mr}$. Edmond Savary for his technical assistance. We also thank Roussel UCLAF, Romainville, France for the generous gift of RU 16709 .

Correspondence should be addressed to Dr. L. Tapia-Arancibia, Laboratoire de Neurobiologie Endocrinologique, URA 1197 CNRS, Université Montpellier II, Place Fugène Bataillon, F-34095 Montpellier, Cedex 5, France.

Copyright (C) 1995 Society for Neuroscience $0270-6474 / 95 / 160130-07 \$ 05.00 / 0$
}

one on luteinizing hormone-releasing hormone release from mediobasal hypothalamic slices.

A mechanism involved in the nongenomic effect of steroids involves binding to a membrane-bound receptor complex, such as those for inhibitory, e.g., GABA (Majewska et al., 1986), and/or excitatory, e.g., NMDA neurotransmitters (Smith, 1987; Paul and Purdy, 1992; Mellon, 1994). Some steroids may potentiate or inhibit NMDA receptor-mediated responses (Smith et al., 1987; Wu et al., 1991; Irwin et al., 1992, 1994; Park-Chung et al., 1994), and they can also have agonistic or antagonist $\mathrm{GABA}_{\mathrm{A}}$ receptorlike activity (Paul and Purdy, 1992).

Interestingly, two of the neuroactive steroids that are the most potent negative modulators of $\mathrm{GABA}_{\mathrm{A}}$ receptors, $3 \alpha-$ hydroxy-5 $\alpha$-pregnan-20-one (allopregnanolone), which is the primary metabolite of progesterone, and allotetrahydrodeoxycorticosterone, derived from deoxycorticosterone, have been measured in brain and plasma, where their levels fluctuated in response to stress and during the estrus cycles of female rats (Paul and Purdy, 1992). In normal male rats, for example, allopregnanolone is detectable in the cerebral cortex and hypothalamus, its level being markedly and rapidly increased after acute swim stress (Purdy et al., 1991) or acute elcctroshock (Korneyev et al., 1993).

Taken together, these data strongly suggest that neurosteroids represent a new class of neuromodulators that can rapidly alter neuron excitability via nongenomic mechanisms. However, little information is available on the molecular mechanisms, particularly the excitatory ones, that may explain the rapid membrane effects of steroid hormones. Consequently, the aim of the present study was to examine the effect of allopregnanolone on intracellular calcium level $\left(\left[\mathrm{Ca}^{2+}\right]_{i}\right)$ in primary cultures of rat hypothalamic neurons by performing high-time resolution photometric measurements of $\left[\mathrm{Ca}^{2+}\right]_{i}$ transients evoked by drug application. 


\section{MATERIALS AND METHODS}

Chemicals. Most of the standard chemicals, tetrodotoxin (TIX), EGIA, 17ß-estradiol, progesterone, pertussis toxin (PTX), and nifedipine, were obtained from Sigma (St. Louis, MO). Fura-2 AM and Pluronic F-127 were purchased from Molecular Probes (Eugene, OR). Allopregnanolone ( $3 \alpha$-hydroxy- $5 \alpha$-pregnan-20-one or $3 \alpha, 5 \alpha$-THP or RU 16709) was kindly provided by Roussel UCL $A F$ (Romainville, France)

Cell culture. Primary cultures were prepared by mechanoenzymatic dissociation of fetal (day 17) Sprague-Dawley rat hypothalami as described previously (Tapia-Arancibia et al., 1988) with necessary modifcations. Briefly, cells were plated onto chambered cover glass (Lab-Tek $\mathrm{N}^{\circ} 178565$, Nunc, Naperville, IL) coated previously with poly-D-lysine (10 $\mu \mathrm{g} / \mathrm{ml} ; M_{\mathrm{r}} 220 \mathrm{kDa}$ ) and preincubated for $1 \mathrm{hr}$ with $10 \%$ fetal calf serum in Minimum Essential Medium (MEM; Gibco, Grand Island, NY). Cells were seeded in growth medium composed of MEM supplemented with $\mathrm{Nu}$ serum (10\%) (Collaborative Research, Lexington, MA), glucose $(0.6 \%)$, glutamine $(2 \mathrm{mM})$, and penicillin-streptomycin $(2.5 \mathrm{U} / \mathrm{ml})$, adjusted to $\mathrm{pH} 7.3$. The cultures were maintained at $37^{\circ} \mathrm{C}$ in a humid atmosphere $\left(95 \%\right.$ air $\left./ 5 \% \mathrm{CO}_{2}\right)$. The proliferation of non-neuronal cells was inhibited by treatment with $10 \mu \mathrm{M}$ cytosine-arabinoside for $48 \mathrm{hr}$ between days 3 and 5 after plating. Three days before the experiments, a phenol red-free medium supplemented with $10 \%$ charcoal-treated $\mathrm{Nu}$ serum (devoid of steroids) was used. Experiments were performed after $8 \mathrm{~d}$ in culture.

Measurements of intracellular free calcium in single neurons. The $\left[\mathrm{Ca}^{2+}\right]_{\mathrm{i}}$ was determined from the intensity of the fluorescence signal with the $\mathrm{Ca}^{2+}$-sensitive indicator Fura-2. Hypothalamic neurons in culture were washed with a serum-free medium (Locke's buffer) containing (in $\mathrm{mM}$ ): $\mathrm{NaCl} 140, \mathrm{KCl} 5$, glucose $10, \mathrm{KH}_{2} \mathrm{PO}_{4} 1.2, \mathrm{MgSO}_{4} 1.2, \mathrm{CaCl}_{2} 1.8$, HEPES 10 , adjusted to $\mathrm{pH} 7.4$ with $\mathrm{NaOH}$. The osmolarity of the buffer was 300-310 mOsm $/ \mathrm{kg}$. Cells were loaded with Fura-2 AM, which was dissolved first in water-free dimethyl sulfoxide (DMSO) and then diluted with Locke's buffer to a final concentration of $2.5 \mu \mathrm{M}$ Fura-2 AM, which containing $0.02 \%(\mathrm{w} / \mathrm{v})$ Pluronic F-127. The DMSO concentration in these mixtures was $<0.01 \%$. Dye loading was carried out for $30 \mathrm{~min}$ in a humidified $\mathrm{O}_{2} / \mathrm{CO}_{2}$ incubator at $37^{\circ} \mathrm{C}$. Subsequently, loaded cells were washed with Locke's buffer and the cover glass was mounted on the microscope stage. The fluorescence measurements were performed with buffer and drug solutions that were maintained at $36-37^{\circ} \mathrm{C}$ throughout the measuring period.

Fast fluorescence photometer system. $\left[\mathrm{Ca}^{2+}\right]_{i}$ in single cells was measured by the method described by Lambert et al. (1994) with necessary modifications. Briefly, the Zeiss (Oberkochen, Germany) photometer system was based on an inverted microscope (Axiovert 100) equipped for epifluorescence. Interference filters of $340 / 10$ and $380 / 10 \mathrm{~nm}$ were mounted alternately $(200 \mathrm{~Hz})$ on the filter wheel, and excitation light was deflected through an oil-immersion objective (Zeiss-plan Neoflaur 100X $1.30, \mathrm{Ph} 3$ ). Fluorescence emission from individual cells was viewed through a diaphragm adjusted to the cell size. To minimize the background noise of the Fura- 2 signals, successive values were averaged to a final resolution of $320 \mathrm{msec}$. With fluorescence values corrected for background and dark current, calculation of $\left[\mathrm{Ca}^{2+}\right]_{\mathrm{i}}$ was carried out from the ratio between 340 and $380 \mathrm{~nm}$ recordings, in accordance with the equation given by Grynkiewicz et al. (1985): $\left[\mathrm{Ca}^{2+}\right]_{\mathrm{i}}=K_{\mathrm{d}} \times(R-$ $\left.R_{\min }\right) /\left(R_{\max }-R\right) \times \beta$. To calculate $\left[\mathrm{Ca}^{2+}\right]_{\mathrm{j}}$ values from measured data, the parameters $K_{\mathrm{d}}=224, R_{\min }=0.203, R_{\max }=6.351$, and $\beta=3.418$ were specified in the calibration menu.

Solutions and drug application. Stock solutions $\left(10^{-2} \mathrm{M}\right)$ of the steroids dissolved in ethanol were prepared daily and then diluted with Locke's buffer containing TTX $(1 \mu \mathrm{M})$. All steroid solutions $(10 \mu \mathrm{l})$ were applied within $5 \mathrm{sec}$ directly in the proximity of the recorded neurons $(10 \mu \mathrm{l}$ in a total volume of $200 \mu \mathrm{l}$ ) using a motor-driven syringe (I Iamilton-microlab 900, speed setting 9; Bonaduz, Switzerland). The final concentration of ethanol in these solutions was $<0.01 \%$. Ethanol $(0.01 \%)$ has no effect by itself on basal $\left[\mathrm{Ca}^{2+}\right]_{\mathrm{j}}$. This method allowed reproducible changes in the medium surrounding a selected neuron and appeared to ensure fast concentration changes. Calcium-free medium (EGTA-buffer) contained (in mM): EGTA 2, $\mathrm{NaCl} 140, \mathrm{KCl} 5$, glucose $10, \mathrm{KH}_{2} \mathrm{PO}_{4} 1.2, \mathrm{MgSO}_{4} 1.2$, and HEPES 10, pH 7.4. In this EGTA buffer, $100 \mathrm{nM}$ free $\mathrm{Ca}^{2+}$ (which corresponds to the resting $\left[\mathrm{Ca}^{2+}\right]_{i}$ as determined with Fura-2 measurements) was maintained.

Data analysis. Results were expressed as mean \pm SEM. The statistical evaluation was performed by Student's $t$ test. The estimations of $\mathrm{EC}_{50}$ and its standard error were determined with a Marquardt-Levenberg nonlin- ear least-squares curve-fitting algorithm (Origin, Microcal Software, Northampton, MA)

\section{RESULTS}

\section{Effect of allopregnanolone on intracellular calcium}

The basal level of $\left[\mathrm{Ca}^{2+}\right]_{\mathrm{i}}$ in hypothalamic neurons was $71 \pm 8 \mathrm{nM}$ (mean $\pm \mathrm{SEM}, n=21$ ).

Applications $(60-120 \mathrm{sec})$ of allopregnanolone ( $1 \mathrm{pM}$ to 100 nM) evoked a marked increase of $\left[\mathrm{Ca}^{2+}\right]_{\mathbf{i}}$, reaching a peak rise within 2-3 sec in 85 of 113 neurons tested. Two distinct types of $\left[\mathrm{Ca}^{2+}\right]_{i}$ responses were observed: (1) in a great majority of neurons $(67 / 85,79 \%)$, allopregnanolone induced a brief, single, transient $\left[\mathrm{Ca}^{2+}\right]_{\mathrm{i}}$ rise that decayed to near resting levels in $<30 \mathrm{sec}$ in the continued presence of the steroid (see, for example, 10 and $100 \mathrm{~nm}$ in Figs. $1 A, 2,3 B, 4$, and $6 B$ ); and (2) allopregnanolone triggered a single, sustained rise in $\left[\mathrm{Ca}^{2+}\right]_{\mathrm{i}}(18 / 85$ neurons, $21 \%)$ with a plateau phase, decaying very slowly throughout the measuring period (see, for example, $1 \mathrm{nM}$ in Figs. $1 A, 3 A$, and $6 A$ ).

Figure $1 A$ shows the increases in $\left[\mathrm{Ca}^{2+}\right]_{\mathrm{i}}$ induced by increasing concentrations of allopregnanolone. In six neurons tested, a significant rise in $\left[\mathrm{Ca}^{2+}\right]_{i}$ is observed by steroid concentrations as low as $1 \mathrm{pm}$. Nllopregnanolone elicits a concentration-dependent in crease in $\left[\mathrm{Ca}^{2+}\right]_{i}$ within the range of $1 \mathrm{pM}$ to $100 \mathrm{nM}$. Maximal response is obtained at $100 \mathrm{nM}$, and the estimated $\mathrm{EC}_{50}$ value for allopregnanolone is $10 \pm 4 \mathrm{~nm}$ (Fig. $1 B$ ).

Successive applications of allopregnanolone evoked a similar $\left[\mathrm{Ca}^{2+}\right]_{i}$ rise. Figure 2 shows the $\left[\mathrm{Ca}^{2+}\right]_{i}$ rise in response to two repetitive applications of $1 \mathrm{~nm}$ allopregnanolone. Four neurons lested displayed similar profiles. This result allowed us to use for some experiments the same neuron as its own control, thus diminishing the effect of individual variation among neurons.

\section{Blockade of allopregnanolone-induced changes in $\left[\mathrm{Ca}^{2+}\right]_{i}$}

To investigate whether the allopregnanolone-induced $\left[\mathrm{Ca}^{2+}\right]_{\mathrm{i}}$ rise was dependent on the presence of external $\mathrm{Ca}^{2+}$, allopregnanolone-sensitive neurons that showed a rise in $\left[\mathrm{Ca}^{2+}\right]_{i}$ in the presence of $1.8 \mathrm{mM} \mathrm{Ca}^{2+}$ were treated with the steroid in EGTA buffer. Figure $3 A$ shows that the allopregnanolone-induced $\left[\mathrm{Ca}^{2+}\right]_{i}$ rise was reduced significantly in the presence of EGTA buffer. In the presence or absence of $\mathrm{Ca}^{2+}$ in the external medium, the $\left[\mathrm{Ca}^{2+}\right]_{\mathrm{i}}$ rise induced by $10 \mathrm{nM}$ allopregnanolone was 466 \pm 32 and $178 \pm 10 \mathrm{nM}$, respectively $(p<0.01, n=9)$. As shown in Figure $3 A$ (right), there was still a small residual response to allopregnanolone in the absence of external $\mathrm{Ca}^{2+}$, and this was observed consistently in all nine neurons tested. To examine whether the $\mathrm{Ca}^{2+}$ influx could involve voltage-sensitive $\mathrm{Ca}^{2+}$ channels, we tested the L-type, dihydropyridine-sensitive $\mathrm{Ca}^{2+}$ channel blocker nifedipine (Fig. $3 B$ ). Nifedipine $(10 \mu \mathrm{M})$ applied $30 \mathrm{sec}$ before and during the application of $10 \mathrm{~nm}$ allopregnanolone diminished by $75 \pm 12 \%(n=8)$ the calcium rise induced by allopregnanolone: $133 \pm 23$ vs $545 \pm 43 \mathrm{~nm}$ (control) $(p<0.01, n=8)$. These experiments, with or without nifedipine, were performed on the same neurons.

\section{Specificity of allopregnanolone effect on $\left[\mathrm{Ca}^{2+}\right]_{i}$}

Two different approaches were used to define pharmacologically the steroid specificity. First, we investigated the ability of two other steroids (progesterone and $17 \beta$-estradiol) to increase $\left[\mathrm{Ca}^{2+}\right]_{i}$ in the hypothalamic neurons. Progesterone (10 $\mathrm{nM}$ to $1 \mu \mathrm{M}$ ) had no significant effect on $\left[\mathrm{Ca}^{2+}\right]_{i}$. In these experiments, the mean $\left[\mathrm{Ca}^{2+}\right]_{i}$ values obtained in the absence or presence of $10 \mathrm{~nm}$ progesterone were 89 
Figure 1. Dose-dependent effect of allopregnanolone $(3 \alpha, 5 \alpha-T H P) . A$, Traces represent changes in $\left[\mathrm{Ca}^{2+}\right]_{\mathrm{i}}$ induced by increasing concentrations of allopregnanolone (0.001-100 nM) measured in a single neuron. Each stimulus was separated by 5 min intermission after washing twice in normal Locke's buffer. $B$ shows the dose-response relationship of evoked $\left[\mathrm{Ca}^{2+}\right]_{i}$ increase (mean $\pm \mathrm{SEM}$ ) as a function of allopregnanolone concentration. Data were obtained from several neurons (sample size is given in brackets) for a given concentration tested randomly. ${ }^{*} p<0.01 ;{ }^{* *} p<$ 0.001 vs control without allopregnanolone.

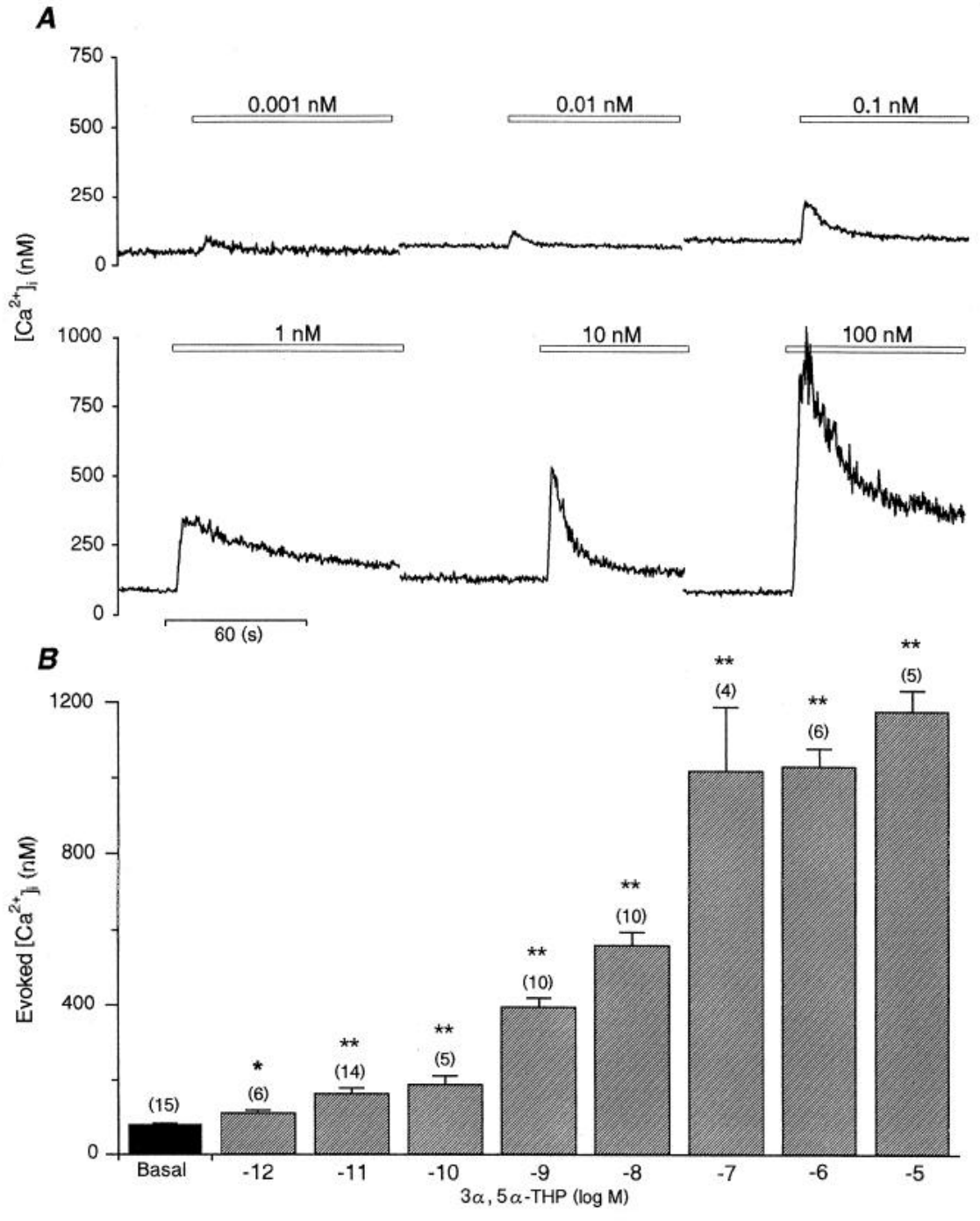

\pm 9 and $106 \pm 5 \mathrm{nM}$, respectively $(p>0.05, n=7)$. Similarly, progesterone applied at higher concentration did not significantly affect the $\left[\mathrm{Ca}^{2+}\right]_{\mathrm{i}}$ levels $(p>0.05, n=6)$, which ranged between 79

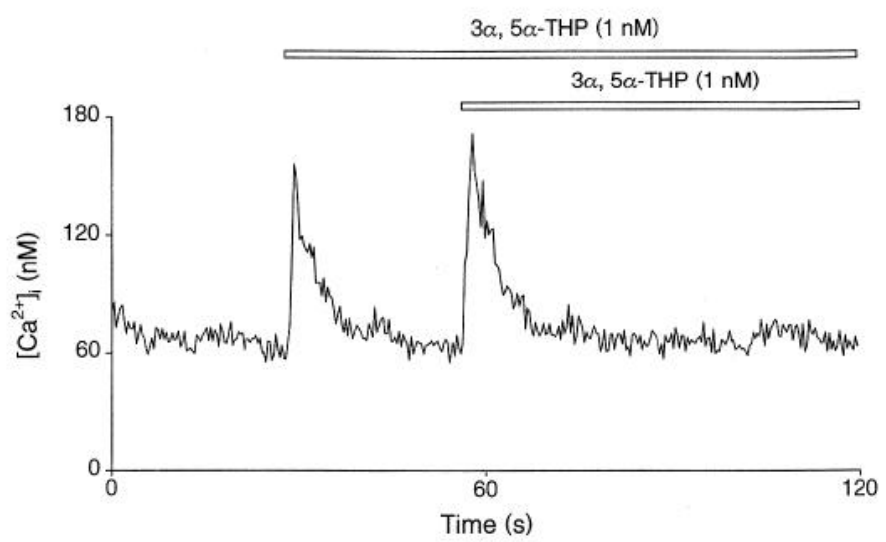

Figure 2. Successive allopregnanolone $(3 \alpha, 5 \alpha-T H P)$ applications on $\left[\mathrm{Ca}^{2+}\right]_{i}$ increase. A selected neuron was subjected to two successive applications of allopregnanolone $(1 \mathrm{nM})$. The resting $\left[\mathrm{Ca}^{2+}\right]_{\mathrm{i}}$ had returned to prestimulation level before the second application. Note that the amplitude of $\left[\mathrm{Ca}^{2+}\right]_{\mathrm{i}}$ response induced by allopregnanolone is unchanged. Four neurons displayed similar profiles. $\pm 16 \mathrm{nM}$ (control) and $88 \pm 13 \mathrm{nM}(1 \mu \mathrm{M}$ progesterone). Interestingly, these nonresponding neurons to progesterone exhibited a remarkable $\left[\mathrm{Ca}^{2+}\right]_{\mathrm{i}}$ rise to $10 \mathrm{~nm}$ allopregnanolone (mean peak value: $533 \pm 96 \mathrm{~nm}, n=6)$. In contrast, $17 \beta$-estradiol evoked $\left[\mathrm{Ca}^{2+}\right]_{\mathrm{i}}$ increase to a lesser extent than allopregnanolone: $17 \beta$-estradiol $(100$ nM)-induced $\left[\mathrm{Ca}^{2+}\right]_{\mathrm{i}}$ rise peaked at $288 \pm 56 \mathrm{nM}(n=10)$ vs $1022 \pm$ $20 \mathrm{~nm}(n=8)(p<0.01)$ induced by $100 \mathrm{~nm}$ allopregnanolone. The second paradigm consisted of examining the effect of the $\beta$-hydroxylisomer of allopregnanolone. Figure 4 shows that $3 \beta$-hydroxy- $5 \alpha$ pregnan-20-one used at the same concentration of that of the $3 \alpha$ isomer $(1 \mathrm{~nm})$ had no effect on $\left[\mathrm{Ca}^{2+}\right]_{\mathrm{i}}$. However, after washing in Locke buffer the same neuron showed a marked response to allopregnanolone. The resting $\left[\mathrm{Ca}^{2+}\right]_{\mathrm{i}}$ was unchanged after addition of $3 \beta$-hydroxy- $5 \alpha$-pregnan-20-one $(68 \pm 7 \mathrm{nM})$, whereas in the same neurons $3 \alpha$-hydroxy-5 $\alpha$-pregnan-20-one augmented $\left[\mathrm{Ca}^{2+}\right]_{\mathrm{i}}$ up to $327 \pm 37 \mathrm{~nm}(n=7)$.

\section{Lack of effect of PTX on allopregnanolone-induced $\left[\mathrm{Ca}^{2+}\right]_{\mathrm{i}}$}

Hypothalamic neurons were incubated for $20 \mathrm{hr}$ with $100 \mathrm{ng} / \mathrm{ml}$ PTX before loading with Fura-2 AM. $\left[\mathrm{Ca}^{2+}\right]_{i}$ measurements also were carried out in the presence of PTX, which had no significant effect $(p>0.05)$ on allopregnanolone $(10 \mathrm{~nm})$-induced $\left[\mathrm{Ca}^{2+}\right]_{\mathrm{i}}$ rise (Fig. 5). 

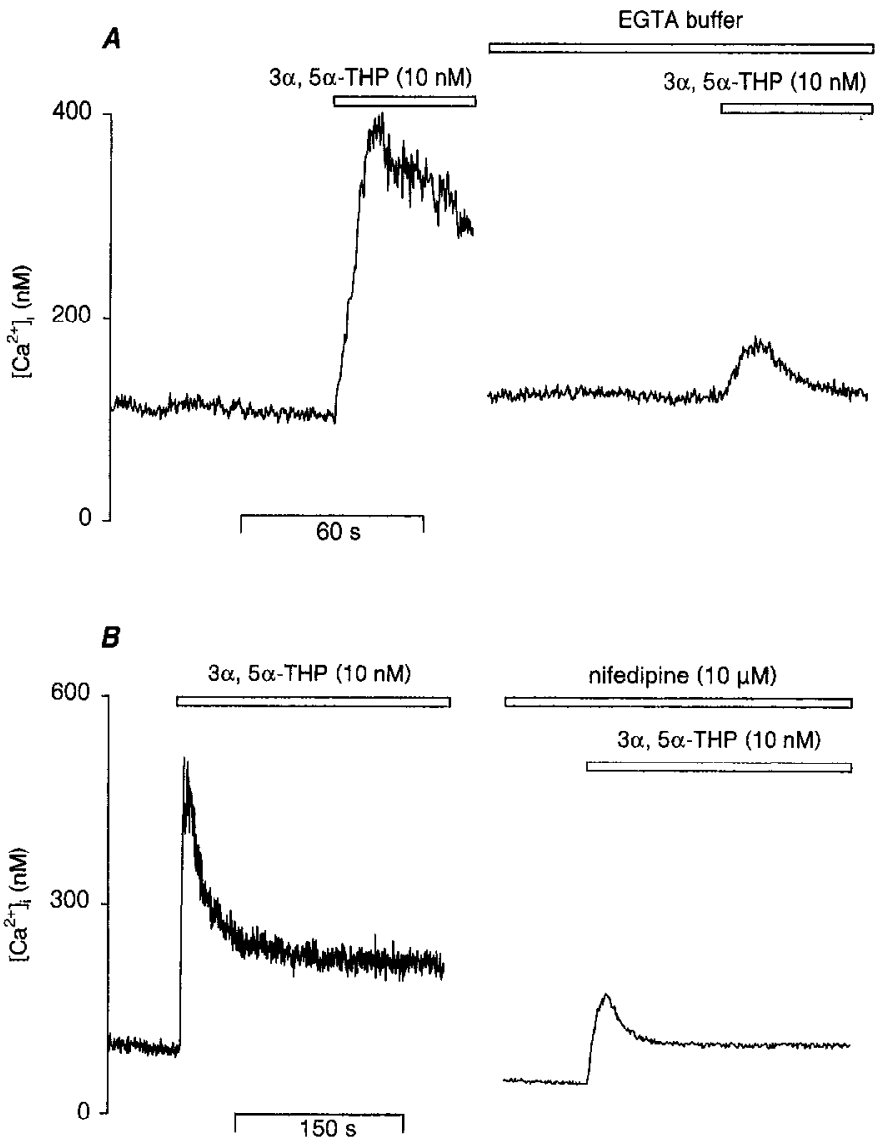

Figure 3. Effect of external $\mathrm{Ca}^{2-1}$ on $\left[\mathrm{Ca}^{2+}\right]_{i}$ increase induced by allopregnanolone $(3 \alpha, 5 \alpha-T H P)$. A, The left panel represents the $\left[\mathrm{Ca}^{2+}\right]_{\mathrm{i}}$ response induced by $10 \mathrm{~nm}$ allopregnanolone in the presence of Lockc's buffer containing $1.8 \mathrm{~mm}$ external $\mathrm{Ca}^{2+}$. Prcincubation of the same neuron in low $\mathrm{Ca}^{2+}$-EGTA buffer (see Materials and Methods) significantly abolished $\left[\mathrm{Ca}^{2+}\right]_{i}$ increase induced by allopregnanolone (right). Nine neurons displayed similar profiles when tested under similar conditions. $B$, Effect of L-type channel blocker, nifedipine, on $\left[\mathrm{Ca}^{2+}\right]_{\mathrm{i}}$ increase induced by allopregnanolone $(3 \alpha, 5 \alpha-T H P)$. Left, Control $\left[\mathrm{Ca}^{2+}\right]_{i}$ response induced by $10 \mathrm{nM}$ allopregnanolone. Right, After washing, the same neuron was preincubated for $30 \mathrm{sec}$ with $10 \mu \mathrm{M}$ nifedipine and then subjected to $10 \mathrm{~nm}$ allopregnanolone. The $\left[\mathrm{Ca}^{2+}\right]_{\mathrm{i}}$ response induced by allopregnanolone is markedly decreased by the L-channel blocker. Nine neurons displayed similar profiles when tested under similar conditions.

\section{Inhibitory effect of picrotoxin and bicuculline on allopregnanolone-induced $\left[\mathrm{Ca}^{2+}\right]_{i}$}

In an attempt to determine whether the $\left[\mathrm{Ca}^{2+}\right]_{i}$ rise induced by allopregnanolonc involved $\mathrm{GABA}_{\mathrm{A}}$ receptor participation, wc performed a series of experiments with and without picrotoxin or bicuculline (Fig. 6) using the same neurons as their own control. Picrotoxin $(10 \mu \mathrm{m})$ applied simultaneously with $10 \mathrm{~nm}$ allopregnanolone inhibited by $65 \pm 7 \%$ the intracellular $\mathrm{Ca}^{2+}$ response to allopregnanolone: $422 \pm 41$ vs $150 \pm 27 \mathrm{nM}(p<0.01, n=11)$ (Fig. $6 A$ ). Bicuculline $(50 \mu \mathrm{M})$ applied simultaneously with $10 \mathrm{~nm}$ allopregnanolone completely blocked (Fig. $6 B$ ) the peak of $\left[\mathrm{Ca}^{2+}\right]_{\mathrm{i}}$ rise induced by allopregnanolone: $434 \pm 55$ vs $47 \pm 5 \mathrm{nM}$ $(n=8)$ (Fig. 6B).

\section{DISCUSSION}

This is, to our knowledge, the first study showing very rapid stimulatory cffect of a ncurosteroid, allopregnanolone, on cytosolic free $\mathrm{Ca}^{2+}$ in central nervous system neurons. The peak was reached within 2-3 sec after allopregnanolone application and is one of the most rapid membrane effects of a steroid to be reported. It may be comparable with that observed for the activation of calcium channels by progesterone in plasma membranes of human sperm (Blackmore et al., 1990), or with the effect of steroids on electrical activity of nerve cells occurring when applied locally (Robel and Baulieu, 1990; McEwen, 1991a).

Our results suggest that allopregnanolone-induced $\left[\mathrm{Ca}^{2+}\right]$, rise is dependent mainly on the presence of extracellular $\mathrm{Ca}^{2+}$. Indeed, EGTA buffer strongly reduced the increased response to allopregnanolone. In addition, $\sim 70 \%$ of the allopregnanoloneinduced increase in $\left[\mathrm{Ca}^{2+}\right]_{i}$ is inhibited by nifedipine, suggesting that part of the calcium influx occurs via voltage-gated calcium channels of L-type, which have been described in these cells (Tapia-Arancibia and I Iumbert, 1991; Desarménien et al., 1994; Dayanithi et al., 1995). These experiments also clearly show that there is still a residual $\left[\mathrm{Ca}^{2+}\right]_{i}$ response to allopregnanolone. This response may be attributable to the involvement of intracellular $\mathrm{Ca}^{2+}$ stores (Simpson et al., 1995) or to the involvement of other voltage-activated $\mathrm{Ca}^{2+}$ channel types (Hofman et al,, 1994). Further experiments are necessary to characterize this residual response to allopregnanolone. However, $\mathrm{GABA}_{\mathrm{A}}$ receptors seem to be involved in the $\left[\mathrm{Ca}^{2+}\right]_{\mathrm{i}}$ rise induced by allopregnanolone, as suggested by the inhibitory effect of picrotoxin and bicuculline.

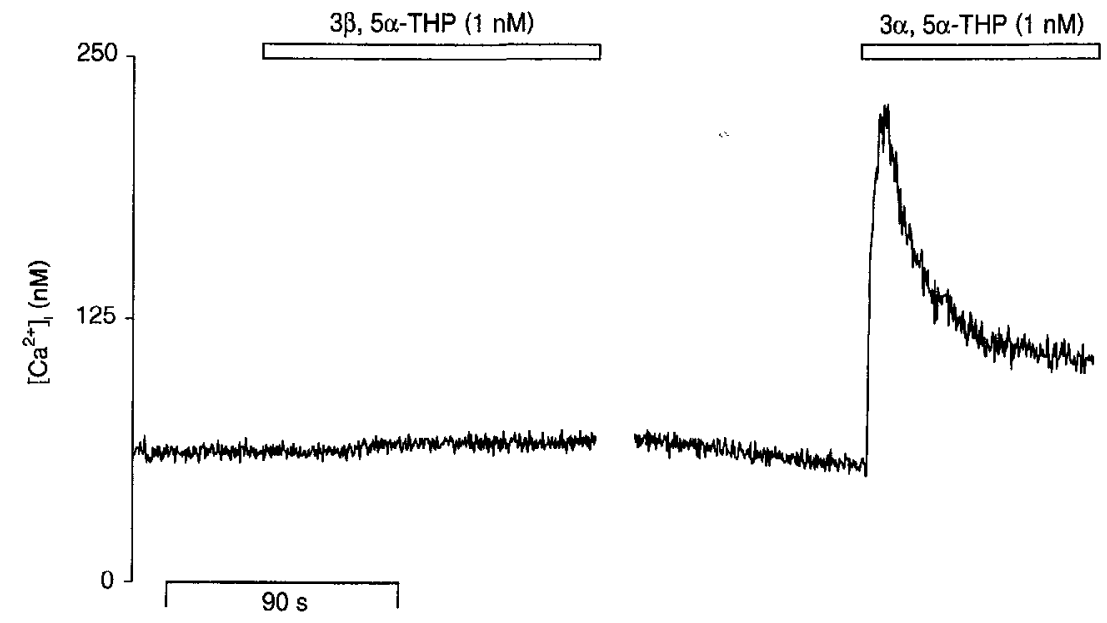

Figure 4. Specificity of allopregnanolone $(3 \alpha, 5 \alpha-T H P)$ on $\left[\mathrm{Ca}^{2+}\right]_{\mathrm{i}}$ rise. $L$ eft, $\Lambda$ selected neuron was subjected first to the isomer $3 \beta, 5 \alpha$-THP (1 nM). Right, After washing, the same neuron exhibited a marked $\left[\mathrm{Ca}^{2+}\right]_{i}$ increase when the isomer $3 \alpha, 5 \alpha$-THP (1 nM) was applied. Seven neurons displayed similar profiles. 


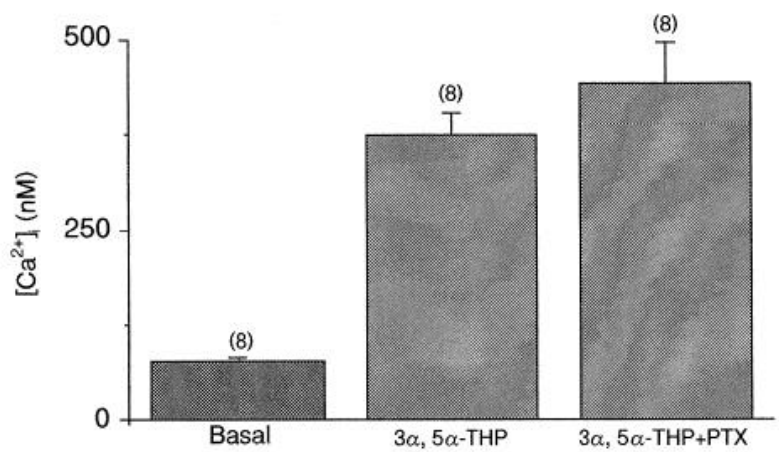

Figure 5. Lack of effect of PTX on $3 \alpha, 5 \alpha$-THP-induced $\left[\mathrm{Ca}^{2+}\right]_{\mathrm{i}}$ rise. The culture dishes were incubated for $20 \mathrm{hr}$ with $(n=8)$ or without $(n=8) 100$ $\mathrm{ng} / \mathrm{ml}$ PTX and then were tested with $10 \mathrm{~nm}$ allopregnanolone. Diagram represents basal levels of $\left[\mathrm{Ca}^{2+}\right]_{i}$ and allopregnanolone-evoked $\left[\mathrm{Ca}^{2+}\right]_{i}$ increase in control neurons, and the response to allopregnanolone in the presence of PTX in PTX-treated neurons.

This is consistent with a potentiation by allopregnanolone of a $\mathrm{GABA}_{\mathrm{A}}$-mediated depolarization of neurons that secondarily may allow opening of voltage-sensitive calcium channels. We have shown previously, using the same experimental model, that GABA is released tonically in the incubation medium from hypothalamic neurons (Rage et al., 1992, 1993). According to this interpretation, it has been shown that in developing cortical neurons (Yuste and Katz, 1991), in cultured cerebellar granule cells (Connor et al., 1987), and in hippocampal neurons in the early postnatal life (Cherubini et al., 1991) GABA is able to depolarize cells.

The allopregnanolone-induced $\left[\mathrm{Ca}^{2+}\right]_{\mathrm{i}}$ rise is dose-dependent, saturable, stereoselective, and specific because it is not mimicked by the $3 \beta$-hydroxy isomer or by progesterone. A significant effect is produced by concentrations as low as $1 \mathrm{pm}$ with a maximum at $100 \mathrm{~nm}$, allowing us to envisage that such an effect might be physiologically relevant if it were corroborated in adult rats. In fact, during proestrus in female rats, plasma progesterone levels may rise to micromolar concentrations (Smith et al., 1975). Furthermore, allopregnanolone and allotetrahydrodeoxycorticosterone plasma levels rise during stress from concentrations lower than nanomolars to reach concentrations near of $10 \mathrm{~nm}$ (Purdy et al., 1991). Moreover, enzymes in the brain also can generate active metabolites from the parent steroids (i.e., progesterone), and local concentrations of the neuroactive steroids may reach high nanomolar concentrations because of the contribution from the local production. Thus, the progesterone concentration in the brain of normal rats can oscillate between 5 and 22 nм (Purdy et al., 1991; Korneyev et al., 1993) and can increase up to 55-65 nm after electroshock (Korneyev et al., 1993) and up to 20-42 nM after swimming stress (Purdy et al., 1991). Allopregnanolone concentration in normal rat brain is $2-4$ $\mathrm{nm}$ and can increase up to 10-20 nM after swimming stress (Purdy et al., 1991) or up to 4-9 nm after acute electroshock (Korneyev et al., 1993). Because of the range of concentrations of progesterone and metabolites measured in plasma and brain, it seems reasonable to envisage that if the effect reported here is corroborated in vivo in adult rats, it could have a physiological relevance in some of these particular conditions.

It is well established that local target tissue metabolism is an important factor in the mechanism of action of steroid hormones. $5 \alpha$-Dihydroprogesterone and allopregnanolone are the primary metabolites of progesterone accumulating in adult (Karavolas and Hodges, 1990) and fetal brain (Barnea et al., 1990). The site of formation of allopregnanolone is predominantly the brain (Corpéchot et al., 1993), and the enzyme activities that catalyze these

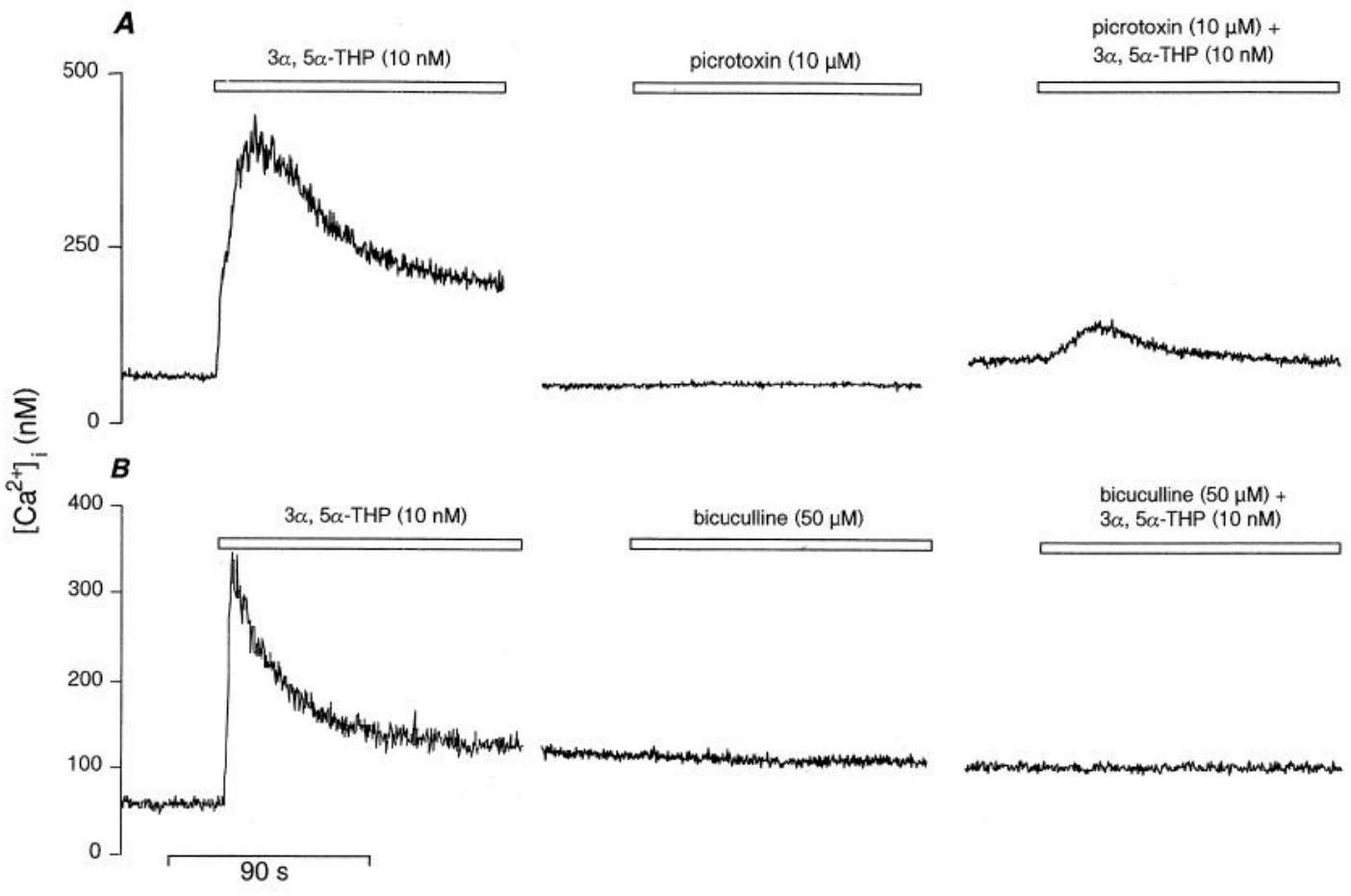

Figure 6. Effect of picrotoxin $(A)$ and bicuculline $(B)$ on $3 \alpha, 5 \alpha$-THP-induced $\left[\mathrm{Ca}^{2+}\right]_{\mathrm{i}}$ rise. $A, B$ : Left, Control $\left[\mathrm{Ca}^{2+}\right]_{\mathrm{i}}$ responses induced by 10 nM allopregnanolone. Middle, When applied alone, $10 \mu \mathrm{M}$ picrotoxin $(A)$ and $50 \mu \mathrm{M}$ bicuculline $(B)$ did not significantly modify resting $\left[\mathrm{Ca}^{2+}\right]_{\mathrm{i}}$ level. Right, $\left[\mathrm{Ca}^{2+}\right]_{\mathrm{i}}$ responses evoked by simultaneous application of $10 \mu \mathrm{M}$ picrotoxin plus $10 \mathrm{nM}$ allopregnanolone $(A)$ and $50 \mu \mathrm{M}$ bicuculline plus $10 \mathrm{nM}$ allopregnanolone $(B)$. 
conversions are expressed strongly in the hypothalamus and anterior pituitary (Karavolas and Hodges, 1990). Both $5 \alpha$-reductase and $3 \alpha$-reductase activities are affected by the estrus cycle with peak activities at proestrus, estrus, and metestrus (Karavolas and Hodges, 1990). In addition, the hypothaiamus and the anterior pituitary specifically accumulate significant amounts of radiolabeled $5 \alpha$-dihydroprogesterone and progesterone, the two substances being the precursors of allopregnanolone. $\left[{ }^{3} \mathrm{H}\right]$ progesterone also is metabolized to $5 \alpha$-dihydroprogesterone and allopregnanolone in male rat hypothalamic slices (Korneyev et al., 1993). These data clearly show that the adult rat hypothalamus is equipped with the enzymes and substrates for the synthesis of neurosteroids, and these also may be modulated in vivo by the ovarian cycle in the femalc.

Neurotransmitter and neurohormone release depend on calcium, and the modulation of calcium availability within the cell (either an increase in immature tissue or a decrease in adult tissue) may represent an important mechanism of action of active steroids at the cell surface. However, few reports are available on the regulatory effect of neurosteroids on calcium conductances or calcium concentrations in the central nervous system. Whole-cell patch-clamp studies in freshly isolated adult guinea pig hippocampal CA1 pyramidal neurons show that micromolar concentrations of allotetrahydrodeoxycorticosterone, dehydroepiandrosterone sulfate, and pregnanolone depress voltage-gated calcium currents (ffrench-Mullen and Spence, 1991). This effect also is reproduced by pregnenolone and pregnenolone sulfate but not by progesterone (Spence et al., 1991). This inhibition of calcium currents by the steroids seem to be mediated by a PTX-sensitive G-protein associated with the activation of PKC (french-Mullen et al., 1994). But in cultured rat hippocampal neurons, high concentrations of pregnenolone sulfate failed to alter basal $\left[\mathrm{Ca}^{2+}\right]_{i}$ or to modify the $\mathrm{K}^{+}$-induced $\left[\mathrm{Ca}^{2+}\right]_{\mathbf{i}}$ rise, as measured by microspectrofluorimetry and the calcium-sensitive indicator Fura-2. However, at these concentrations $(5-250 \mu \mathrm{M})$, the steroid potentiated the NMDA-induced rise of $\left[\mathrm{Ca}^{2+}\right]_{i}$ in a dose-dependent manner (Irwin et al., 1992).

The possible functional significance that in developing neurons allopregnanolone may potentiate GABA-induced depolarization leading to an increased $\mathrm{Ca}^{2+}$ influx is not clear. It is possible that it is involved in the development or modification of inhibitory synapses in hypothalamic circuits.

In conclusion, the present data are consistent with the presence of a receptor or recognition site for allopregnanolone at or close to the cell surface, probably associated to $\mathrm{GABA}_{\mathrm{A}}$ receptors, leading to changes in $\left[\mathrm{Ca}^{21}\right]_{j}$ in hypothalamic neurons. These findings may open up entirely new areas of investigation, because rapid calcium changes induced by neurosteroids may represent a link of the metabolic cascade whereby hypothalamic neurons control the short-term process of release.

\section{REFERENCES}

Barnea A, Hajibeigi A, Trant JM, Mason I (1990) Expression of steroid metabolizing enzymes by aggregating fetal brain cells in culture: a model for developmental regulation of the progesterone $5 \alpha$-reductase. Endocrinology 127:500-502.

Baulieu EE (1981) Steroid hormones in the brain: several mechanisms? In: Steroid hormone regulation of the brain (Fuxe K, Gustafsson JA, Wetterberg L, eds), pp 3-14. Oxford: Pergamon.

Baulieu EE (1991) Neurosteroids: a new function in the brain. Biol Cell $71: 3-10$.

Blackmore PF, Beebe SJ, Danforth DR, Alexander N (1990) Progesterone and $17 \alpha$-hydroxyprogesterone: novel stimulators of calcium influx in human sperm. J Biol Chem 265:1376-1380.
Cherubini E, Gaiarsa JL, Ben-Ari Y (1991) GABA: an excitatory transmitter in early postnatal life. Trends Neurosei 14:515-519.

Connor JA, Tseng HY, Hockberger PE (1987) Depolarization- and transmitter-induced changes in intracellular $\mathrm{Ca}^{2+}$ of rat cerebellar granule cells in explant cultures. J Neurosci 7:1384-1400.

Corpéchot C, Young J, Calvel M, Wehrey C, Veltz JN, Touyer G, Mouren M, Prasad VVK, Banner C, Sjövall J, Baulieu EE, Robel P (1993) Neurosteroids: $3 \alpha$-hydroxy-5 $\alpha$-pregnan-20-one and its precursors in the brain, plasma, and steroidogenic glands of male and female rats. Endocrinology 133:1003-1009.

Dayanithi G, Rage F, Richard P, Tapia-Arancibia L (1995) Characterization of spontaneous and $N$-methyl-D-aspartate-induced calcium rise in rat-cultured hypothalamic neurons. Neuruendocrinology 61:243-255.

Desarménien MG, Devic E, Rage F, Dayanithi G, Tapia-Arancibia L, Richard P (1994) Synchronous development of spontaneous and evoked calcium-dependent properties in hypothalamic neurons. Dev Brain Res 79:85-92.

Drouva SV, Laplante E, Kordon C (1985) Progesterone-induced LHRH release in vitro is an estrogen-as well as $\mathrm{Ca}^{2+}$-and calmodulindependent secretory process. Neuroendocrinology 40:325-331.

ffrench-Mullen JMH, Danks P, Spence KT (1994) Neurosteroids modulate calcium currents in hippocampal CA1 neurons via a pertussis toxin-sensitive G-protein-coupled mechanism. J Neurosci 14:1963-1977.

ffrench-Mullen JMH, Spence KT (1991) Neurosteroids block $\mathrm{Ca}^{2}$ ' channel current in freshly isolated hippocampal CA1 neurons. Eur J Pharmacol 202:269-272.

Grynkiewicz G, Poenie M, Tsien RY (1985) A new generation of $\mathrm{Ca}^{2+}$ indicators with greatly improved fluorescence properties. J Biol Chem 260:3440-3450.

Hofmann F, Biel M, Flockerzi V (1994) Molecular basis for $\mathrm{Ca}^{2+}$ channel diversity. Annu Rev Neurosci 17:399-418.

Irwin RP, Lin SZ, Rogawski MA, Purdy RH, Paul SM (1994) Steroid potentiation and inhibition of $N$-methyl-D-aspartate receptor-mediated intracellular $\mathrm{Ca}^{2+}$ responses: structure-activity study. J Pharmacol Exp Ther 271:677-682.

Irwin RP, Maragakis NJ, Rogawski MA, Purdy RH, Farb DH, Paul SM (1992) Pregnelonone sulfate augments NMDA receptor mediated increases in intracellular $\mathrm{Ca}^{2+}$ in cultured rat hippocampal neurons. Neurosci Lett 141:30-34.

Karavolas HJ, Hodges DR (1990) Neuroendocrine metabolism of progesterone and related progestins. In: Steroids and neuronal activity (Ciba Foundation Symposium 153, ed), pp 22-55. Chichester: Wiley.

Korneyev A, Guidotti A, Costa E (1993) Regional and interspecies differences in brain progesterone metabolism. J Neurochem 61:2041-2047.

Lambert RC, Dayanithi G, Moos FC, Richard P (1994) Isolated supraoptic cells respond to oxytocin by a rise in intracellular $\mathrm{Ca}^{2+}$ concentration. J Physiol (Lond) 478:275-287.

Majewska MD, Harrison NL, Schwartz RD, Barker JL, Paul SM (1986) Steroid hormone metabolites are barbiturate-like modulators of the GABA receptor. Science 232:1004-1007.

McEwen BS (1991a) Steroid hormones are multifunctional messengers to the brain. Trends Endocrinol Metab 2:62-67.

McEwen BS (1991b) Non-genomic and genomic effects of steroids on neural activity. Trends Pharmacol Sci 12:141-147.

Mellon SH (1994) Neurosteroids: biochemistry, modes of action, and clinical relevance. J Clin Endocrinol Metab 78:1003-1008.

Orchinik M, McEwen B (1993) Novel and classical actions of neuroactive steroids. Neurotransmissions 9:1-6.

Park-Chung M, Wu FS, Farh DH (1994) $3 \alpha$-Hydroxy-5 $\beta$-pregnan20-one sulfate: a negative modulator of the NMDA-induced current in cultured neurons. Mol Pharmacol 46:146-150.

Paul SM, Purdy RH (1992) Ncuroactive stcroids. FASEB J 6:2311-2321.

Purdy RH, Morrow AL, Moore PH, Paul SM (1991) Stress-induced elevations of $\gamma$-aminobutyric acid type A receptor-active steroids in the rat brain. Proc Natl Acad Sci USA 88:4553-4557.

Rage F, Benyassi A, Arancibia S, Tapia-Arancibia L (1992) $\gamma$-Aminobutyric acid-glutamate interaction in the control of somatostatin release from hypothalamic neurons in primary culture: in vivo corroboration. Endocrinology 130:1056-1062.

Rage F, Jalaguier S, Rougeot C, Tapia-Arancibia L (1993) GABA inhibition of somatostatin gene expression in cultured hypothalamic neurons. NeuroReport 4:320-322.

Ramirez VD, Dluzen DE, Ke FC (1990) Effects of progesterone and its metabolites on neuronal membranes. In: Steroids and neuronal 
activity (Chadwick D, Widdows K, eds), pp 125-144. Chichester: Wiley.

Robel P, Beaulieu EE (1990) Les neurostérö̈des: une nouvelle fonction du cerveau? Medicine Sciences 6:252-260.

Robel P, Beaulieu EE (1994) Neurosteroids: biosynthesis and function. Trends Endocrinol Metab 5:1-8.

Schumacher M (1990) Rapid membrane effects of steroid hormones: an emerging concept in neuroendocrinology. Trends Neurosci $13: 359-362$.

Simpson PB, Challiss RAJ, Nahorski SR (1995) Neuronal $\mathrm{Ca}^{2+}$ stores: activation and function. Trends Neurosci 18:299-306.

Smith MS, Freeman ME, Neill JD (1975) The control of progesterone secretion during the estrous cycle and early pseudopregnancy in the rat: prolactin, gonadotropin and steroid levels associated with rescue on the corpus luteum of pseudopregnancy. Endocrinology 96:219-226.

Smith SS, Waterhouse BD, Chapin JK, Woodward DJ (1987) Progesterone alters GABA and glutamate responsiveness: a possible mechanism for its anxiolytic action. Brain Res 400:353-359.
Spence KT, Plata-Salaman CR, ffrench-Mullen JMH (1991) The neurosteroids pregnenolone and pregnenolone-sulfate but not progesterone, block $\mathrm{Ca}^{2+}$ currents in acutely isolated hippocampal CA1 neurons. Life Sci 49:235-239.

Tapia-Arancibia L, Humbert T (1991) Activation of dihydropyridinesensitive calcium channels induces somatostatin release from hypothalamic neurons. Pharmacological characterization. Neurochem Int 18:367-371.

Tapia-Arancibia L, Parès-Herbuté N, Astier H, Reichlin S, Nathanson $\mathrm{J}$ (1988) Adenylate cyclase activation is not sufficient to stimulate somatostatin release from dispersed cerebral cortical and diencephalic cells in glia-free cultures. Brain Res 450:101-110.

Wu FS, Gibbs TT, Farb DH (1991) Pregnenolone sulfate: a positive allosteric modulator at the $N$-methyl-D-aspartate receptor. Mol Pharmacol 40:333-336.

Yuste R, Katz LC (1991) Control of postsynaptic $\mathrm{Ca}^{2+}$ influx in developing neocortex by excitatory and inhibitory neurotransmitters. Neuron 6:333-344. 